\title{
Restoration of sensation in paraplegia by a sensory innervated plantar fillet free flap. Case report
}

\author{
JA Goldberg $^{1}$, WJ Barwick (deceased) ${ }^{2}$ and LS Levin ${ }^{3}$ \\ ${ }^{1}$ Missouri Bone \& Joint Clinic, 3165 McKelvey Road, Suite 100, St Louis, MO 63044; ${ }^{2}$ Associate Professor, \\ ${ }^{3}$ Assistant Professor, Division of Orthopaedic Surgery and Division of Plastic, Maxillofacial and Oral Surgery \\ Box 3945, Duke University Medical Center Durham, North Carolina 27710, USA
}

\begin{abstract}
Sensory denervation most likely is the key factor to the multiple physiological derangements that predispose paraplegic patients to recurrent decubitus ulceration. A sensory innervated plantar free flap offers the ability to provide soft tissue coverage and to regain sensory innervation of the ulcer prone area in patients with recurrent ulceration. We present a patient in which an innervated plantar free flap was used to restore sensation to the sacral area in a patient with recurrent ulceration.
\end{abstract}

Keywords: sensory flaps; paraplegia; sacral pressure ulceration

\section{Introduction}

There are many factors which predispose paraplegic patients to decubitus ulcer formation. These include malnutrition, fecal incontinence, increased length of paralysis, social state of the patient, and smoking. ${ }^{1}$ Denervation is associated with reduced soft tissue thickness, ${ }^{2}$ poorer wound healing ${ }^{3}$ and an inability to recognize excess pressure levels. ${ }^{1}$ These factors combine to lead to ulcer recurrence. Early series reported recurrence rates of $26 \%-45 \%$, while a series of patients at a spinal cord specialty center still had, albeit reduced, an $11 \%$ recurrence rate. ${ }^{4-6}$ The restoration of sensory innervation below the level of spinal cord injury which innervates these pressure prone areas would most likely prevent ulcer formation. Until the time when this becomes feasible, other methods of sensory restoration of the tissue used for ulcer closure must be entertained.

\section{Case report}

\section{Materials and methods}

The patient is a 47 -year-old male T12 paraplegic of 21 years duration. Multiple local rotation flaps had been performed for sacral, ischial and trochanteric ulcers. The patient presented with a $10 \mathrm{~cm} \times 12 \mathrm{~cm}$ class IV sacral ulcer (Figure 1). Sensation was intact at the T12 level. Prior to definitive wound closure, an ileal loop and colostomy were performed. A plantar fillet free flap was harvested with the neurovascular pedicle divided at the tibio-peroneal bifurcation (Figures 2, 3). The leg was revised to a below the knee amputation. The T10 and T11 intercostal nerves were dissected distally to the abdominal wall sensory branches

This paper was presented at the International Symposium of Plastic Surgery, August, 1993, Stockholm, Sweden and Poster, American Society of Reconstructive Microsurgery, September, 1993, Kansas City, Missouri, USA
(Figure 4). The posterior tibial vessles were anastomosed in an end-to-end fashion to the superior gluteal vessels. The

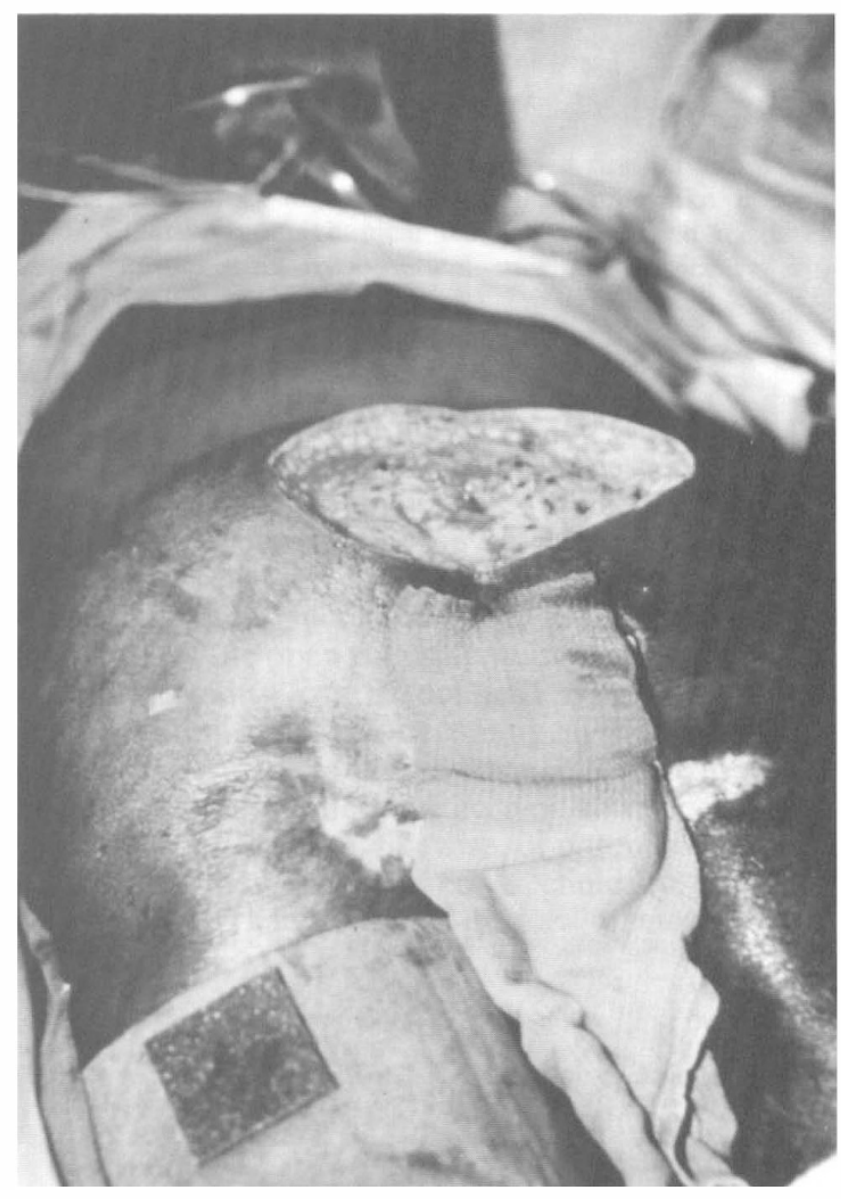

Figure 1 Recurrent $10 \mathrm{~cm} \times 12 \mathrm{~cm}$ class IV sacral ulcer 


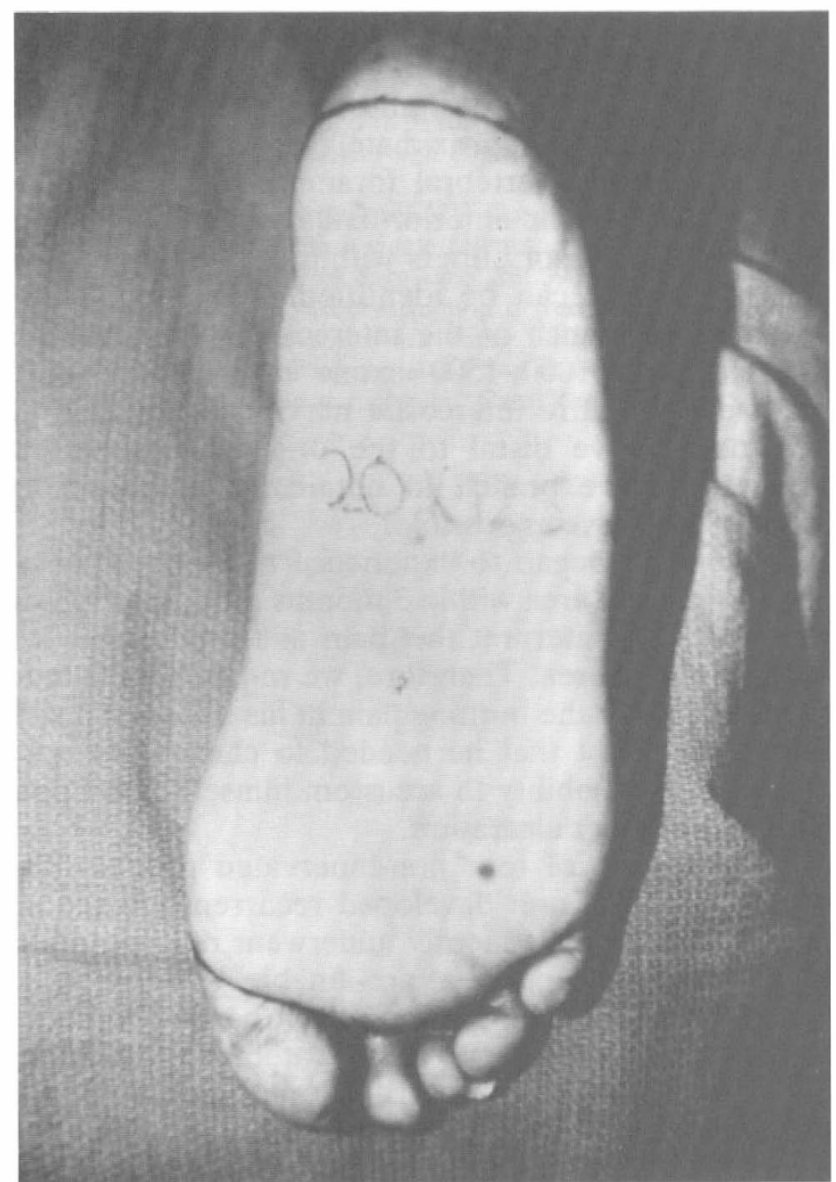

Figure 2 Plantar fillet free flap based upon the posterior tibial neurovascular pedicle

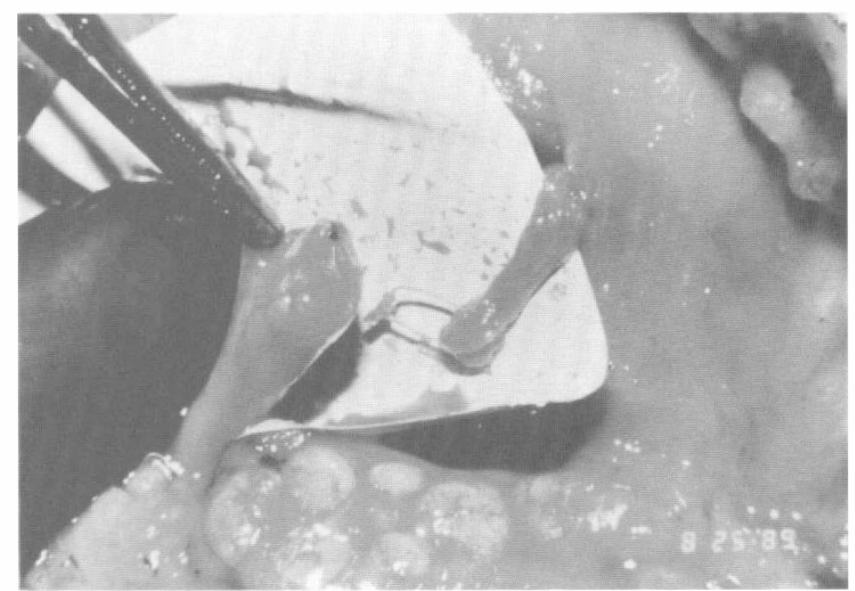

Figure 3 Plantar fillet free flap based upon the posterior tibial neurovascular pedicle

posterior tibial nerve demonstrated active bleeding after the microvascular anastomoses (Figure 5).

\section{Results}

The surgical course was without complications. The patient was discharged 2 weeks after surgery. The patient devel-

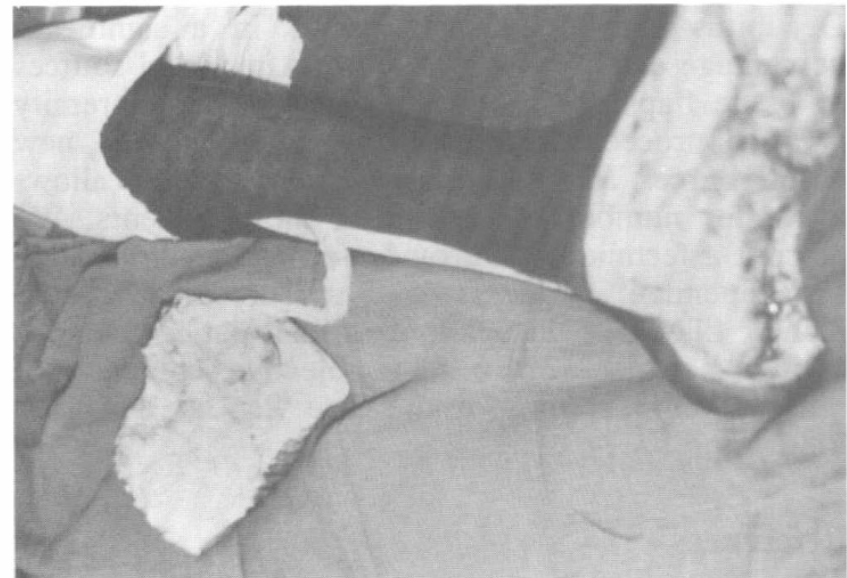

Figure 4 The T10 and T11 intercostal nerves were neurotized to the posterior tibial nerve

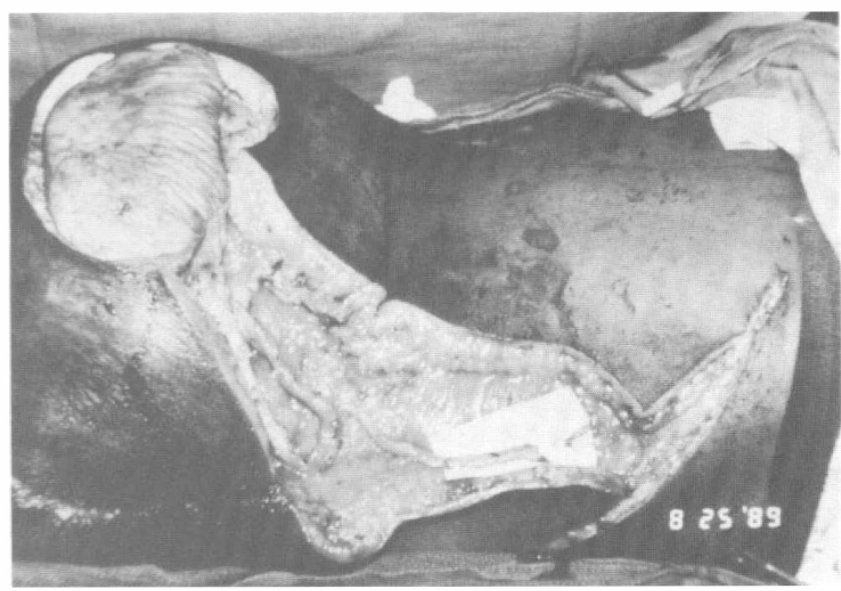

Figure 5 Active bleeding from the posterior tibial nerve after microvascular anastomoses were completed

oped sensation in the flap within 3 months. A burning pain occurred as a result of extended sacral pressure. This sensation was referred to the right anterior abdominal wall and groin areas. Once the patient was re-educated to interpret the anterior abdominal pain as sacral pressure, he was able to prevent excessive and prolonged sacral pressure.

At the 4 year follow-up, the patient demonstrated light touch, sharp pain, and deep pressure sensation of the plantar fillet free flap (Figure 6). He lacked two point discrimination. Vibratory testing demonstrated recognition of both 30 and 256 cycles per second (Hertz) tuning forks. However, recognition of both was diminished from areas above the level of denervation. Biopsy demonstrated viable nerve fibers in the subdermal tissue. He has had no recurrent ulceration (Figure 7).

\section{Discussion}

Closure of decubitus ulcers can be performed with skin grafts, skin flaps, and muscle flaps. ${ }^{3-7}$ As sources of local tissue flaps are consumed, the lower extremity is 


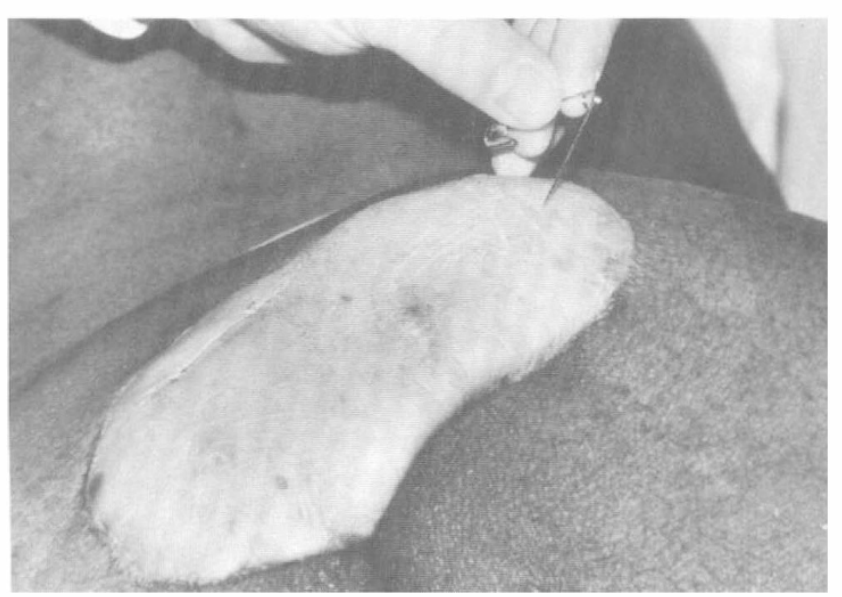

Figure 6 Sensibility testing 4 years after surgery

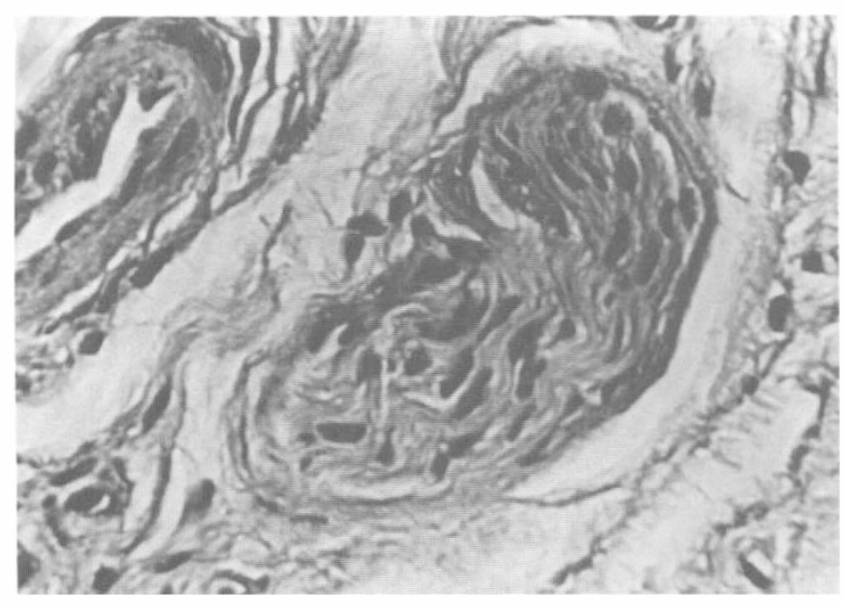

Figure 7 Hematoxylin-eosin stain demonstrated viable nerve fibers in subdermal tissue

sacrificed to create new tissue sources. ${ }^{8}$ The advent of microvascular surgical technique has led to new sources from which to obtain adequate tissue for ulcer closure. ${ }^{9,10}$

There are several described methods to provide sensate tissue flaps to sites of previous ulceration. ${ }^{11-13}$ Both Dibbell $^{11}$ and Daniel ${ }^{12}$ relied on the transfer of skin innervated by the intercostal nerves. The disadvantages of these techniques included multiple stages for flap transfer, incremental sensory loss after each state and the small area of tissue that can be eventually transferred to the ulcer. Louis $e t a l^{13}$ later described the transfer of the medial antebrachial cutaneous nerve to the lateral femoral cutaneous nerve to provide sensation to a tensor fascia lata flap for closure of an ischial ulcer. Coleman et al ${ }^{14}$ later transferred the intercostal nerves to the lateral femoral cutaneous nerve also to innervate a tensor fascia lata flap.

Our technique relies on a vascularized and innervated plantar fillet free flap..$^{15}$ The posterior tibial nerve functioned as a vascularized nerve graft. The posterior tibial nerve was coapted to two intercostal nerves from above the spinal cord injury level. The intercostal nerves contain both motor and sensory axons. ${ }^{16}$ These nerves consist of approximately $55 \%-65 \%$ sensory axons at the paravertebral foramina level, and $70 \%$ sensory axons at the anterior axillary line. There is no set pattern of sensory fibers within the nerve so that a separate bundle can be identified. The lateral cutaneous nerve branch of the intercostal nerve contains approximately $1000-1500$ axons of the $5500-8500$ axons of the entire intercostal nerve. We divided the intercostal nerve distal to the origin of the lateral cutaneous nerve branch to obtain as many sensory axons of the nerve as possible.

The patient began to experience transferred sensation in his groin area within 3 months after surgery. He was unable to interpret this pain as to its connection with the sacral area. Therefore, we re-educated him to understand that the burning pain in his abdominal wall and groin meant that he needed to change his body position. The inability to accustom himself to the pain prevented further ulceration.

Of note, two of four non-innervated plantar fillet free flaps in our unit developed recurrent ulceration. These patients subsequently underwent reconstruction by total thigh flaps. We are unable to draw solid conclusions regarding the long term hardiness of this flap in comparison with non-innervated flaps due to the fact that this is a case report. We are also unable to definitely state whether the recovered sensibility, or another trophic benefit of tissue innervation lead to the long term resistance to ulceration.

\section{Conclusion}

Decubitus ulcer recurrence occurs in a significant percentage of paraplegic patients. After local sources of tissue flaps are exhausted, other lower extremity ablative procedures are performed to provide new tissue sources. Microvascular surgical technique allows a greater number of options in these patients. We present a technique to provide sensory restoration to the dependent surfaces via a sensory reinnervated plantar fillet free flap. The described patient demonstrated both subjective and objective evidence of sensory reinnervation of the free flap at a 4 year follow-up.

\section{References}

1 Crenshaw RP, Vistnes LM. A decade of pressure sore research; 1977-1987. J Rehabil Res Dev 1989; 26: 63-74.

2 Daniel RK et al. Pressure sores and paraplegia: An experimental model. Ann Plast Surg 1985; 15: 41-49.

3 Basson MD, Burney RE. Defective wound healing in patients with paraplegia and quadriplegia. Surg Gynecol Obstet 1982; 155: $9-12$.

4 Harding RL. An analysis of one hundred rehabilitated paraplegics. Plast Reconstr Surg 1961; 27: 235-247.

5 Dansereau JG, Conway $\mathrm{H}$. Closure of decubiti in paraplegics: Report on 2000 cases. Plast Reconstr Surg 1964; 33: 474-480.

6 Hentz VR. Management of pressure sores in a specialty center: A reappraisal. Plast Reconstr Surg 1979; 64: 683-691. 
7 Ger R, Levine SA. The management of decubitus ulcers by muscle transposition: An 8 year review. Plast Reconstr Surg 1976; 58: 419-428.

8 Royer $\mathrm{J}$ et al. Total thigh flaps for extensive decubitus ulcers: A 16 year review of 41 total thigh flaps. Plast Reconstr Surg 1969; 44: $109-118$.

9 Chen H, Weng C, Noordhoff MS. Coverage of multiple extensive pressure sores with a single filleted lower leg myocutaneous free flap. Plast Reconstr Surg 1986; 78: 396-398.

10 Yamamoto $\mathrm{Y}$ et al. Reconstruction of recurrent pressure sores using free flaps. J Reconstr Microsurg 1992; 8: 433-436.

11 Dibbell DG. Use of a long island flap to bring sensation to the sacral area in young paraplegics (Case Report). Plast Reconstr Surg 1974; 54: 220-223.
12 Daniel RK, Terzis JK, Cunningham DM. Sensory skin flaps for coverage of pressure sores in paraplegic patients: A preliminary report. Plast Reconstr Surg 1976; 58: 317-328.

13 Louis $\mathrm{G}$ et al. Medial antebrachial cutaneous-lateral femoral cutaneous neurotization in restoration of sensation to pressurebearing areas in a paraplegic: A four year follow-up. Ann Plast Surg 1987; 19: 572-576.

14 Coleman JJ, Jurkiewicz MJ. Methods of providing sensation to anesthetic areas. Ann Plast Surg 1984; 12: 177-186.

15 Levin LS, Barwick WJ, Goldberg JA. The versatile plantar fillet flap. J Reconstr Surg (submitted).

16 Freilinger G, Holle J, Sulzbruber, SC. Distribution of motor and sensory fibers in the intercostal nerves: Significance in reconstructive surgery. Plast Reconstr Surg 1978; 62: 240-244. 